\title{
Overview of General Living Conditions of People with Disabilities in Albania
}

\author{
Arsen KIlogjri \\ PhD Candidate Clinical for Psychology \\ Tirana European University
}

\begin{abstract}
The aim of this study was the observation of the general situation in which there are people with disabilities in the district of Tirana. As is known, people with disabilities are one of the most vulnerable groups of society. To make a realistic assessment of the situation, we organized direct contacts with some of the persons with disabilities who have attended or recognize the center of care for disabled people.
\end{abstract}

Keywords: Overview, general, living conditions, people, disabilities, Albania

\section{Introduction}

\section{Methodology}

For data collection was used questionnaire method; conversation is conducted directly to the person with disability. The questionnaire contains questions involving different aspects such as:

1- General data: age, residence, marital status, education, the period of the show type and cause of disability, benefits from social care scheme;

2- The health needs of the person, the type of medical benefits, and the type of rehabilitation needed, driving the auxiliary equipment necessary for the individual, the degree of personal autonomy in daily life;

3- information psycho - social on services that benefit, on relations with the surrounding persons, on the way to spend their leisure time, the adequacy of public facilities and private, on the integration of their social (employment, education);

4- Wishes of persons with disabilities.

For this questionnaire was used a sample of 100 people, 50 adults and 50 children. From this sample, 55 were males and 45 females.

The following table shows the distribution of our sample by sex and age

\begin{tabular}{|l|l|l|l|}
\hline Grup mosha & Nr i personave te kontaktuar & Femra & Meshkuj \\
\hline $1-10$ & 32 & 14 & 18 \\
\hline $11-20$ & 21 & 12 & 9 \\
\hline $21-30$ & 11 & 5 & 6 \\
\hline $31-40$ & 18 & 6 & 12 \\
\hline Mbi 40 & 18 & 8 & 10 \\
\hline TOTALI & 100 & 45 & 55 \\
\hline
\end{tabular}



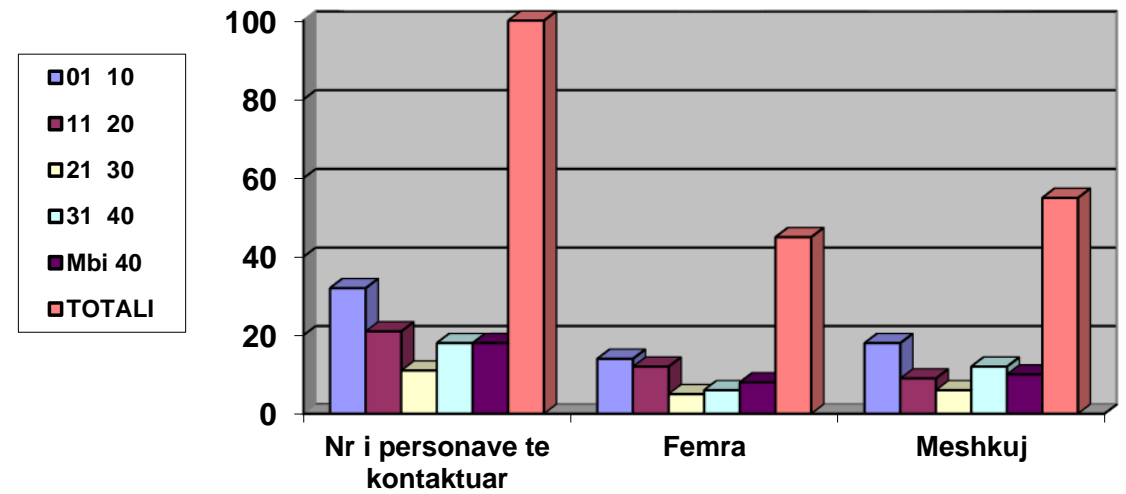

\section{Pathology}

In the studied sample we found four types of pathology, among which, the greatest percentage of occupied physical pathologies (75\%); the sample of adults are involved and the pathologies neuro-motor muscle - skeletal, while, most of the sample of children presents physical-mental disabilities associated with epilepsy (36\%). We are champions of mental pathologies including three minors affected by Down syndrome. In 10\% of cases it has encountered the presence of persons with disabilities in the family, especially between siblings. In $35 \%$ of cases of disability are common symptom appeared during the three years before the birth while in $31 \%$ of cases the persons interviewed have manifested most common symptom that in the moment of birth. The following table presents the distribution of the number of sample study based on pathology

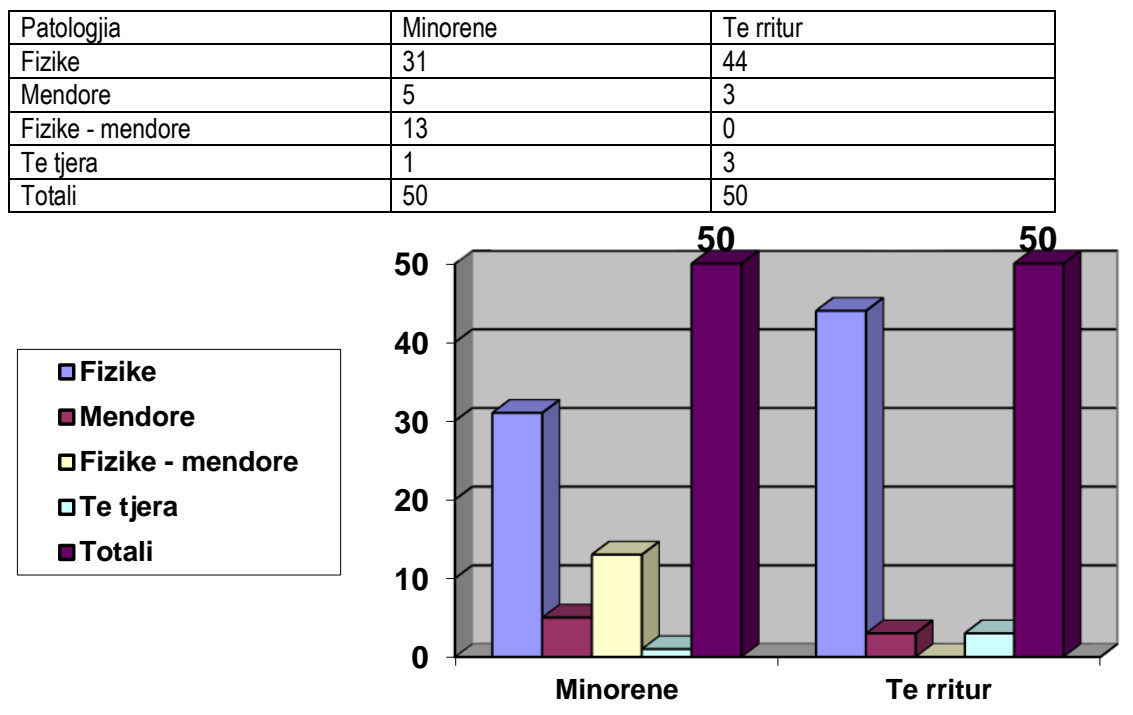

\section{Medical Services}

In the study sample was ascertained that between state and individual health services lacked communication. This communication has been missing with his family. After the acute phase treatment is not advisable or any person informed of the reality of the situation which will be located. Also, few are to be given the information that we run specialized centers for subsequent treatments. Thus, mothers expect their child to develop or to walk without having to follow the sessions of physiotherapy, Logo Pedy (therapy and speech) without being integrated into those few development centers existing, state and raised by NGOs working in this field. 
We have faced the same situation and to an adult who still lives with the dream that was to perform an operation abroad could be counted as once. In fact, people with disabilities should be briefed on the difficult situation in which will be located ranging from moving the bed, the care for personal hygiene, care of wounds decubitus rehabilitation to be attended and finally, the difficulties that will be faced in order to achieve its social integration.

This lack of information is due to the fact that the person falls into a serious depressive state when faced with reality. Information is one of the first services to be provided to individuals and their families. In our opinion, perhaps the time has come the involvement of social workers and psychologists in our hospital personnel structure.

Most respondents stated that medical services are minimal and often corrupt. On the other hand, there is a lack of community knowledge and awareness raising activities on the needs of persons with disabilities, be they medical or social. As a consequence of pathology specifications significant part of persons with disabilities in need of treatment at home. About $58 \%$ of respondents in need of therapy in terms of home.

Asked what benefit medical services, $65 \%$ of respondents replied that does not benefit any public health service. This fact is also bad because it represents a non-compliance of the legislation in force according to which "persons who are in critical condition and unable to be filed in state institutions benefit service in the apartment by the family doctor and the doctor specialist for them procedures that can be performed as an outpatient and indoor conditions. "About $84 \%$ of respondents require more cooperation from employees of healthcare services.

\section{Physiotherapy and aids}

Physiotherapy service is very necessary for people with disabilities. Public structures provide this service in the acute stage pathology but this service is limited and non-continuous. Requests for such services are very high especially in young people. On the other hand, institutions that provide such services are scarce. Here, by means of a table, we presented respondents' needs for rehabilitation service.

\begin{tabular}{|l|l|l|l|l|}
\hline Nevojat & Shume & Mjaft & Pak & Fare \\
\hline Rehabilitim & $85 \%$ & $9 \%$ & $3 \%$ & $3 \%$ \\
\hline
\end{tabular}

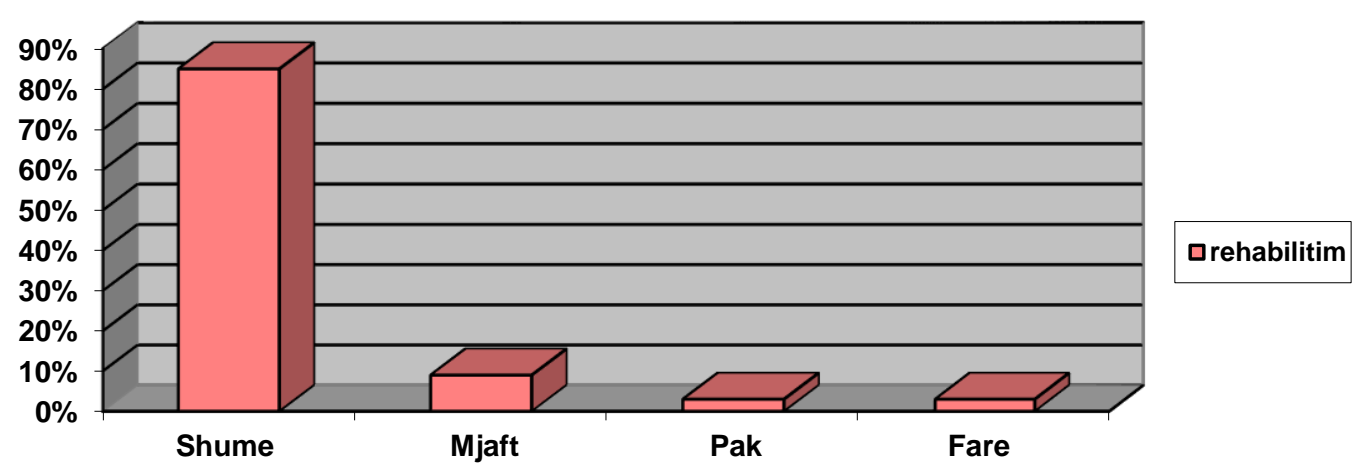

Currently there are NGOs, and not the state, those that mainly covers rehabilitation services. Treatment of persons with disabilities in this kind of service is very necessary because it helps in increasing their personal autonomy. About $59 \%$ of respondents in need of wheelchairs and orthopedic. It would be a step really very important if the state, together with reimbursement of drugs, be able to equip the vehicles mobility and assistive these people (catheters, wheelchairs, mobility means or auxiliary accessories such as bed, the toilet, the sink, in the shower, etc). In assigning such an assessment we have given mainly people with physical pathology. In the majority of cases are NGOs working in the disability field to equip them with these tools persons with disabilities. 


\section{Education}

Preschool and school integration has as main objective the development of people with disabilities in the manner of behavior, in the way of communication with the aim of social integration, and the establishment of bilateral relations with the surrounding environment. 1:10 is the ratio of children born with problems or who suffer a serious injury during birth. Of course, if not done carefully, the child's further development is hindered. State should recognize the principle of equal opportunities for elementary, secondary and higher for children, youth and adults with disabilities, in integrated contexts. The state must ensure that the education of persons with disabilities be an integral part of the state education system.

Currently, in our country there are 12 special education institutions, among which 8 are schools for children with mental retardation, 3 and 2 are day care centers are institutions for children who are disabled or have trouble hearing and eyesight. However, these institutions do not cover all the requirements of the country. In case of occurrence of a serious pathology parents prefer their children to be treated in special institutions. In the absence of the latter the only solution remains emigration abroad or moved to cities where these services are provided.

In cases less severe where children with disabilities mention only physical (disability which constitutes the greatest percentage) and children with learning difficulties, parents try to activate in regular schools. Current law does not prohibit nor does it guarantee such action. We normative provisions of public education in 1996 noted that "the integration of pupils with special hedged in the context of ordinary schools is considered a necessary contemporary process"; on the other hand, this provision does not provide any solution.

A tiny proportion of persons with disabilities manage to complete the 8-year school, but even in these cases, their participation in learning is passive. In most cases these people drop out of school only after 1-2 years of attendance because of the ordeal they experience as the teacher, label them so unethical as well as the mentality of the parents of other children. It should be mentioned that this aspect does not help at all conditions that provide the premises frequented by persons with disabilities; these facilities have not suitable conditions for these people.

Below we present the results of the sample survey on the integration of our education system:

$2 \%$ integrated in preschool;

$16 \%$ attend public schools, more as a listener;

$2 \%$ attend special education;

$2 \%$ attend secondary education;

$2 \%$ attend higher education.

\section{Employment}

Regarding employment, persons with disabilities may consider as the most discriminated population. Their desire to be employed is related not only to economic needs but also social integration. It should be emphasized that the disability payments that they receive is very small in comparison with needs that they present to face everyday life. It is clear that these persons require an appropriate job for them in order to ensure a normal life and achieve a modicum of independence economic. People with disabilities want to be employed and to be integrated into civil society. Staying away those isolated working environments and this exacerbates and more psychological condition. Despite that there is a law which says that "employers are obliged to employ a person with disabilities for every 25 employees other" this law does not apply and always have people remain outside the labor market. As a result, these persons we can introduce the poorest social group in society.

As discussed above we have faced champion interviewed by us. According to our data, only:

$1 \%$ of respondents working full time;

$14 \%$ work part-time;

$85 \%$ do not work at all.

Suitability 
Most people with disabilities makes a poor social life. Causes that exclude these people from social life are numerous. Architectural obstacles that they face not allow to emerge as the built environment is not at all appropriate for them. It is the right of people with disabilities need to be employed to create opportunities, to education, to move smoothly by using the surrounding environment. But the current state of the roads, sidewalks, entrances to buildings, etc., does not ensure such a thing. In fact, there is Law No. 7889 which states: "All new public buildings must provide for the possibility to use different categories of persons with disabilities.

All natural and legal persons that develop projects for public buildings, the environment exterior of the complex, should provide conditions which take into account the interests of persons with disabilities ", but apparently, this law is not applied in practice. According to our survey, $63 \%$ of respondents encountered architectural barriers

Integration

There are few facilities in which persons with disabilities can spend time being felt useful to themselves and to society. These people are forced to exclude yourself from more important activities for their social life. so:

$15 \%$ of respondents do not come at the house;

$29 \%$ stand almost all the time inside;

$19 \%$ are trying to actively make a living out of the house.

Asked what the reasons that they spend time at home are:

$6 \%$ responded that no friends or known and that as a result of long home confinement;

$19 \%$ nowhere to go;

$26 \%$ face of architectural barriers that force them to stay home.

In $63 \%$ of cases the persons interviewed are obliged to come accompanied as inability does not allow them to go alone.

We have encountered many cases in which the parents are those who isolate themselves and their children at home and that hinder their integration. One of the reasons of this isolation is because parents are ashamed to expose a child with disabilities in public places, this due to the environment and mentality where we live. In fact, in our study such a fact we have encountered only in $2 \%$ of cases and this fact shows that the mentality of parents who have a child with disabilities has evolved over time. First time with a child having a shame disable. Today parents trying to activate their children so that they will be much more integrated into society.

Despite the difficult situation in which these people are they trying to do something in life to not sitting back, waiting only from others. They try and commit with all the possibilities to integrate into society. One of the ways of integration is precisely to participation in various associations, especially those that deal with the rights of persons with disabilities.

In our case, $36 \%$ of respondents are members of an association. But his good will to be part of an association of persons stated that currently do not belong to any association; $17 \%$ of respondents expressed a desire to be members of an association, mainly of an association that deals with the rights of persons with disabilities. But, on the other hand, it should be noted that the risk of being member and activist of an association are very limited due to the lack of necessary conditions that the premises must have in order to be frequented by these people.

There are very few activities that are organized for the benefit of persons with disabilities and, consequently, their days are too empty. This negatively affects their psychological state. In fact, $65 \%$ of respondents claimed to have difficulties in the organization of social life.

Regarding social relations, the majority of respondents, $79 \%$ answered that relations with others are generally good and that others understand.

We found that in $69 \%$ of cases among family members and persons with disabilities has more warmth and understanding; family is exactly what many gaps to fill disabled person faces in life. In reality, the family gives a great help on the life of persons with disabilities. 


\section{The Economy}

People with disabilities are layers having major economic problems. Of course, this fact is related to their disability. Given that they are not able to do any kind of work, certainly it very difficult to provide a normal life. Financial income families of persons with disabilities are low. In most cases, the whole family lives only with a disability allowance. This is because almost always a family member is obliged to abandon the work to care for a person with disabilities. Many people eligible to benefit from the law of trusteeship, but a large part of the benefit that no "de facto" because we encounter the offices of the state bureaucracies or simply because you do not know where to turn. Benefiting from this law relatives invalids of the first group, those caring for invalid all the time and, consequently, are unable to be employed.

In terms of custody, we observed that:

$70 \%$ of cases it is the mother who cares for a person with disabilities;

only $1 \%$ of cases are people that provide external assistance they needed.

On the other hand, $78 \%$ of those interviewed stated that they need economic assistance.

It should be emphasized that the situation is even more difficult in other towns and cities, because as we said in the beginning, our study sample is selected in Tirana where socio-economic level is the highest in the entire country.

In $17 \%$ of cases people with disabilities (interviewed) not receiving a disability allowance and this happens not only by the neglect of the individuals themselves, but also the indifference of state authorities, which often do not inform persons with disabilities to their rights and do not provide adequate guidance for the implementation of these rights. There are many shortcomings in the fulfillment of appropriate documentation release in KMCAP and roads to be followed in cases of noninvalidity benefit the group.

The shortcomings faced in the implementation of legislation for people with disabilities and is occasionally they do not benefit the disability group that belongs.

On the other hand it should be noted that persons receiving a disability allowance and complain that it is not at all sufficient to meet the minimum requirements if the person with disability.

\section{Living Environment}

Environment where people with disabilities live, more often, is unsuitable for them. In general, they lack the necessary comfort. Housing spaces in which they live are too small are you leaving him little opportunity to meet their needs. In general, a single room serves as bedroom and kitchen as well. In $35 \%$ of cases the house consists of only one room; $27 \%$ of them has a place sufficient to meet their requirements. Family in which persons with disabilities live, generally is a close nuclear family consisting of parents and children. This occurs in $65 \%$ of cases and only in $5 \%$ of cases the family is living in the open and some generations.

Regarding the problem of water running, we found that, in general, the water is intermittent and in $61 \%$ of cases affirmed that has running water only a few hours a day. We also encountered extreme cases in which water is absent inside the house but provided through wells. This fact is encountered only in $6 \%$ of cases. In $71 \%$ of cases found within the house and the bathroom has hot water and cold. In $6 \%$ of cases there is bathroom inside the house. This fact clearly shows the situation really difficult in which these people live and of course, exacerbates this situation and their more difficult situation.

Often when we talk about people with disabilities, people who think they are not able to care for themselves. In fact this is a very wrong idea which has begun to fight even in our country. Jane created many associations which have begun work to change this wrong mentality. We are faced with many cases in which people with disabilities have achieved notable successes. Today many young people were given the opportunity to attend various training courses in order to develop them, to show their value and manage to integrate fully into society. Their dreams and desires are the same throughout the dreams of others but, unfortunately, the opportunity to realize them is very small.

In our study, $85 \%$ of respondents said they wanted the existence of a socio-educational center-arts where they can develop their skills; On the other hand, $95 \%$ of respondents stressed the great importance of developing a personal training schools in order for them to be able to do something of value in their lives. 


\section{Conclusions}

Given the above reality we are giving our opinion on what is best to be done to reach people with disabilities.

Coordination of services that can provide

prevention

diagnosis

More detailed information on the situation in which will be located

rehabilitation treatment in hospitals that

provision of medical services to families

the creation of specialized rehabilitation centers with specialized staff

establishment of community centers

Mobility device and accessory shop assistant

Intervention social-psycho-pedagogical character in preschool and school;

Flexible learning schedules and improvement of material base;

Legal guarantees for education (law exists but the solutions must also be given);

Suitability construction in the premises of preschool and school education;

The elimination of psychological mismatch between the scientific concept on development and behavior of children and the concept that educators and teachers have currently on their behavior and attitude;

Cooperation not only teachers but parents and a support and cooperation with specialists in the field of disability;

The support of school integration should be not only a teacher but by the entire collective of teaching where a special role, play school departments;

Sensitization of the public, teachers, students and government officials on the merits and advantages of the integration processes.

Municipal or other instances to provide decent jobs for people with disabilities (newsman, different windows)

The state should be as flexible in providing disability benefits

Have a broader understanding of the legislation by persons whose caregivers are entitled foster care payments

State-should enable and control the implementation of existing legislation in the field of accessibility and improving its support

State-also should help in collaboration with private business in the field of design and construction, to understand the importance of adaptability.

\section{References}

[1] Abberley, P. (1997). The Limits of Classical Social Theory in the Analysis and Transformation of Disablement, In Barton, L. and Oliver, M. (Eds), Disability Studies: Past, Present and Future, Leeds: The Disability Press, pp. $25-44$.

[2] Abberley, P. (1998). The Spectre at the Feast: Disabled People and Social Theory, In T. Shakespeare (Ed.), The Disability Reader Social Science Perspectives, London and New York: Cassell, pp. 79 - 93.

[3] Adelman, P. B. \& Vogel, S. A. (1993). Issues in the Employment of Adults with Learning Disabilities, Learning Disability Quarterly, 16(3): 219-232.

[4] Balser, D. B. (2002). Agency in Organizational Inequality: Organizational Behaviour and Individual Perceptions of Discrimination, Work and Occupations, 29(2): 137-165.

Barnatt, S. N. (2008). Social movement diffusion? The case of disability protests in the US and Canada, Disability Studies Quarterly, 28 (1): $1-23$ 